\title{
Bonding through Designing; how a participatory approach to videography can catalyse an emotive and reflective dialogue with young people
}

\author{
Marianne McAra \\ The Institute of Design Innovation, The Glasgow School of Art, Scotland \\ m.mcara1@student.gsa.ac.uk
}

\begin{abstract}
Young people at risk of failing through the educational-net post compulsory schooling, or who have done so already, are too often subsumed under negativebased rhetoric such as disengaged, disaffected, and NEET (Not in Education, Employment or Training). This rhetoric suggests that young people are responsible for their, supposedly, demobilised capacity and fails to acknowledge the fundamental adversities highly disadvantaged young people can face, further camouflaging the most vulnerable. In this paper I reflect on my experience of collaborating with a group of young people, identified by their schoolteachers as vulnerable and at risk of nonparticipation. I reflect on my incremental approach to building and sustaining research bonds, and the catalysing role creativity played. By transporting the technique of Direct Animation into a participatory design context, the participants produced metaphorical videography exploring their ambitions, motivations and anticipations for the future; a conduit through which they explored, translated, and narrated their experiences.
\end{abstract}

Keywords: youth; vulnerable; participatory; bond

\section{Introduction}

In this paper I outline how I have integrated my participatory design practice in my doctoral study to better understand factors that mobilise young people's sense of agency in terms of their future societal participation post compulsory education. I position this work contextually before I critically reflect on my incremental approach to building and sustaining a research relationship with a group of young people identified by their school teachers as at risk, and the catalysing role creativity played. By transporting the technique of Direct Animation into a participatory design context, my aim was to create a safe space and

This work is licensed under a Creative Commons Attribution-NonCommercial 4.0 International License. 
conduit through which the participants could explore, translate, and narrate their experiences and stories (McAra forthcoming 2016). Using this collaborative mode of filmmaking, I describe how the participants produced metaphorical videography exploring their emotional experiences of education. I conclude by setting out some initial findings and methodological insights, nuances of which I believe could resonant with other practitioners and researchers interested in the field of participatory design and youth engagement.

\section{Situating the Invisible Vulnerable}

The Scottish Government (2015) has predicted that approximately 21,000 Scottish young people aged between 16 and 19 are not in education, employment or training, and has ascribed to them the non-participative and stratified label of NEET. Characteristically, this group can include young people who are: young carers; care leavers; those with additional support needs such as a disability; ethnic minority groups; asylum seekers; those with a long term illness; young offenders; low-income family households; living in deprived areas; young people suffering drug or alcohol abuse; and teenage parents; gap year students; young people volunteering; or taking a break from work or studying (Scottish Government 2015; Thompson, Russell and Simmons 2014; Furlong 2006; Scottish Executive 2005).

Fergusson (2013) calls into question the shifting political discourse underpinning nonparticipation, as in the case of the NEET phenomenon. Rather than tackling the causes of social exclusion and marginalisation, the onus is now placed on the individual through the use of such political rhetoric as disengaged, disaffected and underachieving. Fergusson argues that the application of such language "...constructs them as individualised authors of their own (mis)fortunes" (2013 p. 20), suggestive of nonparticipation as a choice to be rectified through initiatives that increase engagement and integration through participation. Rationalising the NEET phenomenon by holding young people responsible for their, supposedly, demobilised capacity, fails to acknowledge fundamental contextual factors and circumstances. In line with Fergusson, I argue that the use of such connotatively loaded rhetoric, which forefronts agency as opposed to the adverse structural circumstances precipitating young peoples' nonparticipation, is furthering marginalisation through a culture of blame.

In addition to its deficit-based connotations, Nudzor (2010) (as well as Simmons, Russell and Thompson 2013; Finlay, et al 2010; Spielhofer, et al 2009; Furlong 2006; and Yates and Payne 2006) problematises the semantics of the NEET acronym as over simplifying a multitude of individual traits and circumstances. As outlined by Furlong, et al (2003), a more comprehensive understanding of how agency, combined with external factors, conditions and available resources, is actualised and harnessed is required in order to establish more effective pro-participation interventions. Researchers such as Levitas, et al (2007), Nudzor (2010), and Whittaker (2010) call for far more inclusive and participatory platforms of representation, empowering a demographic that have been synthesised under negative label, situating young people at the centre of research processes about them. Sweenie is 
Bonding through Designing; how a participatory approach to videography can catalyse an emotive and reflective dialogue with young people

critical of quantitative and arguably generic information about NEETness as underplaying the diversity of this demographic. In her words this is:

"...limited with respect to the understanding of individual experiences, perceptions and aspirations compared to the rich primary data potentially available through engaging in purposeful conversation with these young people" (2009 p. 37).

A top-down political system inevitably adopts outside-looking-in approaches, researching to inform policy reform and service intervention. Recent sociological research has attempted to reverse this; conducting research through a more micro-level qualitative lens, laying emphasis on the point of view of those actually experiencing such reforms and interventions. However, a number of key methodological and ethical challenges have been identified by those researching such a fragile and transient demographic (Harkins and Egan 2013; Nudzor 2010). Official NEET statistics, which are assumed to measure accurately levels and patterns of vulnerability, bypass those who, because of their vulnerable circumstances, are forced into insecure, unsteady or unsuitable employment or training, where they are at increased risk of exploitation, job dissatisfaction, unstable and/or poor working hours, and low levels of pay (Furlong 2006, p. 565-566). Young people in this situation, viewed as having made a successful transition, become excluded from pro-participation interventions. So much focus on making positive transitions and "chasing targets" (Yates and Payne 2006 p. 331) fails to acknowledge those who either have already transitioned but into poor working conditions placing them at increased risk of becoming NEET in the future, or those of a pretransitioning age, still at school but under pressure to leave early or are disenchanted by a perceived lack of opportunities (Nelson and O'Donnell 2012). These groups, the invisible vulnerable, are at risk of falling through the net of care.

Whilst attempting to contextually define the term NEET, I have grown frustrated with its generic and arbitrary measurement of vulnerability. As Furlong calls for "...new ways of capturing vulnerability that go beyond NEET" (2006 p. 567), I seek to explore how my participatory design practice could creatively respond to the needs inherent in the methodological challenges researching 'invisible' vulnerable youth, seeking to reinstate and empower a fragile agency, which has become over-simplified, generalised, or perhaps lost entirely.

\section{Participatory Design}

Unlike traditional forms of design, which typically situate creative authority with the designer, participatory design enables non-designers and the designer to enter into reciprocal dialogues to facilitate and achieve mutual understanding (Broadley 2013; Broadley and McAra 2013; Sanders and Stappers 2008; Simonsen and Robertson 2013). Participatory design can be viewed as a creative discourse of collaborative learning, underpinned by a democratic ideology built upon the socio-political Scandinavian workplace interventions of the 1970's (Simonsen and Robertson 2013). With the status of the expert distributed amongst the collective, participants enter into collaborative partnerships with 
the designer as a dexterous expert of their own indigenous knowledge and "experience domain" (Sleeswijk Visser 2009 p. 5).

So to develop the construction and exchange of knowledge, the use of creative tools support the designer in achieving empathic and contextualized accounts, enabling non-designers to articulate and externalize abstract, often tacit, subjective, experiential and emotive concepts such as identity, values, culture and sense of agency. Working visually, and often taking theoretical and methodological inspiration from disciplines such as sociology, psychology, philosophy and fine art (Koskinen, et al 2011; Sanders 2002; Swann 2002; Zimmerman, Stolterman and Forlizzi 2010), participatory design has an innate ability to stimulate collaborative modes of thinking and communication, whereby a shared language is fostered that traverses disciplinary and hierarchical boundaries (Sanders, 2002). Such a visual dialogue bolsters the egalitarian nature of a participatory design discourse, thus providing a legitimate paradigm for staging research with disempowered demographics through positioning them at the centre of the research, as is the case with this present study.

\section{The Setting}

My fieldwork took place over a fourteen-month period in a Scottish high school located in an area known for high levels of poverty and deprivation. The fifteen young people I collaborated with were aged between fourteen and fifteen and in a Prince's Trust a class, completing their Youth Achievement Award. (The Prince's Trust is a UK wide charity that supports young people in education, employment and training.) This award provides an alternative means to gain a qualification (certified by the Scottish Qualifications Authority), with a curriculum based on activities that will enhance softer skills through additional support such as teamwork, leadership, self-esteem and confidence. This is a two year course with five classes a week, replacing time the participants would have spent in a social subject studying at National Three, Four or Five level (equivalent to the now obsolete Scottish Standard Grades).

The overarching methodological approach of this study was Participatory Action Research (McIntyre 2007; Reason and Bradbury 2006), implemented through a single case study design (Stake 1995; Yin 1994). Reflecting the unpredictability of the context, the fieldwork remained highly explorative in nature, using an emergent methodology that was responsive to the insights that began to surface. I entered into the fieldwork with a loose plan of implementing four methods but was keen to allow the participants and my own intuition to guide exactly when these should be implemented. The four methods were: observation; design workshops; paired and group interviews; and an activity-based focus group. This paper focuses in particular on the first and second of these methods. All names have been changed to protect the participants' identity.

I was invited to attend the class for a double period (1 hour 50 minutes) on a weekly basis, which allowed me crucial time to leave the fieldwork setting and reflect on what had occurred in the classroom that day through writing up extensive field notes (my main mode 
of documentation). This iterative process not only enabled me to reflect critically on what was emerging but also was beneficial during the more applied methods phase (the design workshops and interviews) where I also able to hone my approach and facilitation style in reaction to how it was being received.

\section{Contextual Immersion}

By way of orientating myself within the context, I immersed myself in the classroom for a period of four months. Whilst at the contextual coalface, my aim was to establish trust with the pupils. How exactly this was going to come about, I was unsure, but I was aware from the outset that the pupils would require time to figure me out before any authentic rapport could occur. During this period, the teacher and classroom youth worker enthusiastically encouraged me to join in with their lessons through assertively engaging with and offering assistance to the pupils, particularly during the more creative activities. This presented me with an opportunity to also gain the trust of these two gatekeepers through providing them with additional assistance.

This initial interaction with the pupils was, however, strained and awkward. I too was finding my feet in this situation, overcoming apprehensions, and building up my own confidence in striking up informal conversation with them (McAra forthcoming 2016). Attempts to engage in dialogue were frequently shunned or in many cases ignored altogether. Upon reflection, I started to question whether the pupils' general apathetic response to me was perhaps because they found it difficult to work out where I fitted into the authoritative hierarchy in the classroom, and thus were uncertain about how to behave and conduct themselves around me. I was anxious to persevere in my attempts to engage with the pupils, feeling that as I was the outsider, it was my responsibly to do the legwork. However, more often than not such perseverance was not reciprocated. Overcoming this required me to relinquish control and allow the pupils to determine when they were ready to engage and when they wanted to invite me into their dialogues and interactions.

Towards the end of this of phase, the pupils were presented with the opportunity to take part in an inter-school design competition. Although the topic of the competition was not directly related to my own research, I was allowed to participate by helping the pupils interpret the brief, brainstorm ideas and prototype their concepts. Being able to participate in this, now shared, experience was in fact an incredibly valuable way for me to begin to build up this notion of rapport with the pupils. The competition, although unforeseen and fortuitous, enabled this period of immersion to end with me having something in common with the pupils, a shared point of reference with which to enter the next phase of fieldwork (McAra forthcoming 2016). In the same context of conducting participatory research with atrisk youth, Wearing (2015) refers to this approach in action as cultivating an "experiential bond" between the researcher and participant. Unpacking this relationship further Wearing outlines that: 
"... the researcher and the researched are co-present and co-learn in their knowledge and relationship building through the research... such an ethics entails a shared authenticity, inclusiveness and empathy on the part of the researcher and participants that promotes care, respect, justice, equity and understanding in the qualitative research process... [it] is to "bond" with the worlds of the "other"... The experiential bond is a more complete, sustainable and longer lasting legacy than simply the activities of research over a given period." (2015 p. 65-68, original emphasis)

Wearing suggests such a relationship is based on a reciprocity that goes beyond the ability of research methods to foster. Building upon Wearing's notion of the experiential bond in the context of the competition, I felt that through collaborating with the pupils in undertaking this experience together, sharing in their work, anxiety, excitement and celebrations, I was brought, if only a little, more into their life-worlds, as they were into mine.

\section{Participatory Filmmaking}

My aim for the second phase of fieldwork was to engage with the pupils more directly in a creative project as collaborative participants, to explore more directly themes stemming from my research question on young people's aspirations, motivations and anticipations for their future, post compulsory education. In the same vein as Wilson and Milne (2013) who, when conducting research with young people, described the need for methods to be culturally meaningful, I sought to evolve a visual style and form that would be novel and exciting for the pupils, exploring the method of Participatory Video (Gauntlett 2007, 1998, 1997; Lomax 2011; Lunch and Lunch 2006; Milne, Mitchell and De Lange 2012; Shaw 2012; Yang 2013). As well as being ethically concerned about the implications of using real-world footage in this context, I wanted to provide the participants with a medium that allowed them to go beyond the frame of a camera, to use their own imaginations to engineer creatively any possible vision and expression through drawing. In comparison to the use of technological devices, Literate argues that:

"... drawing is significantly more generative...because one has to actually draw the world into existence, and not merely select aspects of the external environment to record in a video or a photograph." (2013 p. 12)

Furthermore, Heyes highlights the physical bodily activity of drawing, as explorative:

“... thinking-in-action... a particular mode of thinking that goes beyond, or before, ideas in words... [not beginning] with a pre-determined image, but brings the work into being through an intimate and complex relation between the drawer and the drawing." (2010 p. 18 and p. 139)

As opposed to the immediacy of a (video) camera-produced image, drawing demands a deeper mode of engagement with the medium. The intrinsic time for reflective conceptualistion, reinterpreted by the hand, creates a visual depiction capturing the thought processes of the drawer (Gauntlett 2007), who has intuitively entered into a reciprocal dialogue with the self and artifact. Schön (1983) explains that this auto-dialogical transaction 
is a cycle of response, reaction and reflection, suggestive of how tacit knowledge can be externalised through such action.

In order to retain the kinetic quality of film, I wanted to test how participants' drawings could translate into a moving image, or more formally to test the method of Participatory Video as an animation or video collage. Inspired by the pioneering works of Len Lye (19351980), Norman McLaren (1933-1983), Stan Brakeage (1961-2003) and Man Ray's

Rayographs (1923-1929), Direct Animation is a technique whereby illustrations are made directly onto the surface of clear, black or recycled celluloid film, which is then projected through an $8 \mathrm{~mm}, 16 \mathrm{~mm}$ or $32 \mathrm{~mm}$ reel-to-reel projector, projecting film at approximately 24 frames a second. Examples of materials and tools used on the celluloid include: marker pens; inks; bleach; nail and other types of varnish; dental tools for etching; and stitching by hand or with a sewing machine. This technique, as opposed to more conventional forms of animation such as hand-drawn, cut out or stop motion, allows for the rapid production of imagery without the need for highly repetitive actions. This technique also affords the creation of highly abstract imagery, requiring participants to translate their ideas conceptually through metaphors and connotations, working in shapes, colours and textures.

\section{Workshops}

Through weekly workshops, the participants learned how to use these various treatments and created a series of collaborative experimental films. After demonstrating techniques to the pupils at the beginning of each session as a form of master-class, I intentionally left all materials out on one desk for participants to then self-select what they wanted to experiment with, encouraging autonomous learning. At times there was a great deal movement and energy in the classroom as pupils left the confines of their desks. Each week I would also screen the participants' work, enabling them to see what types of shapes and textures had the most visual impact, becoming an effective teaching device, as I witnessed the participants quickly develop their skills (see Figure 1). 

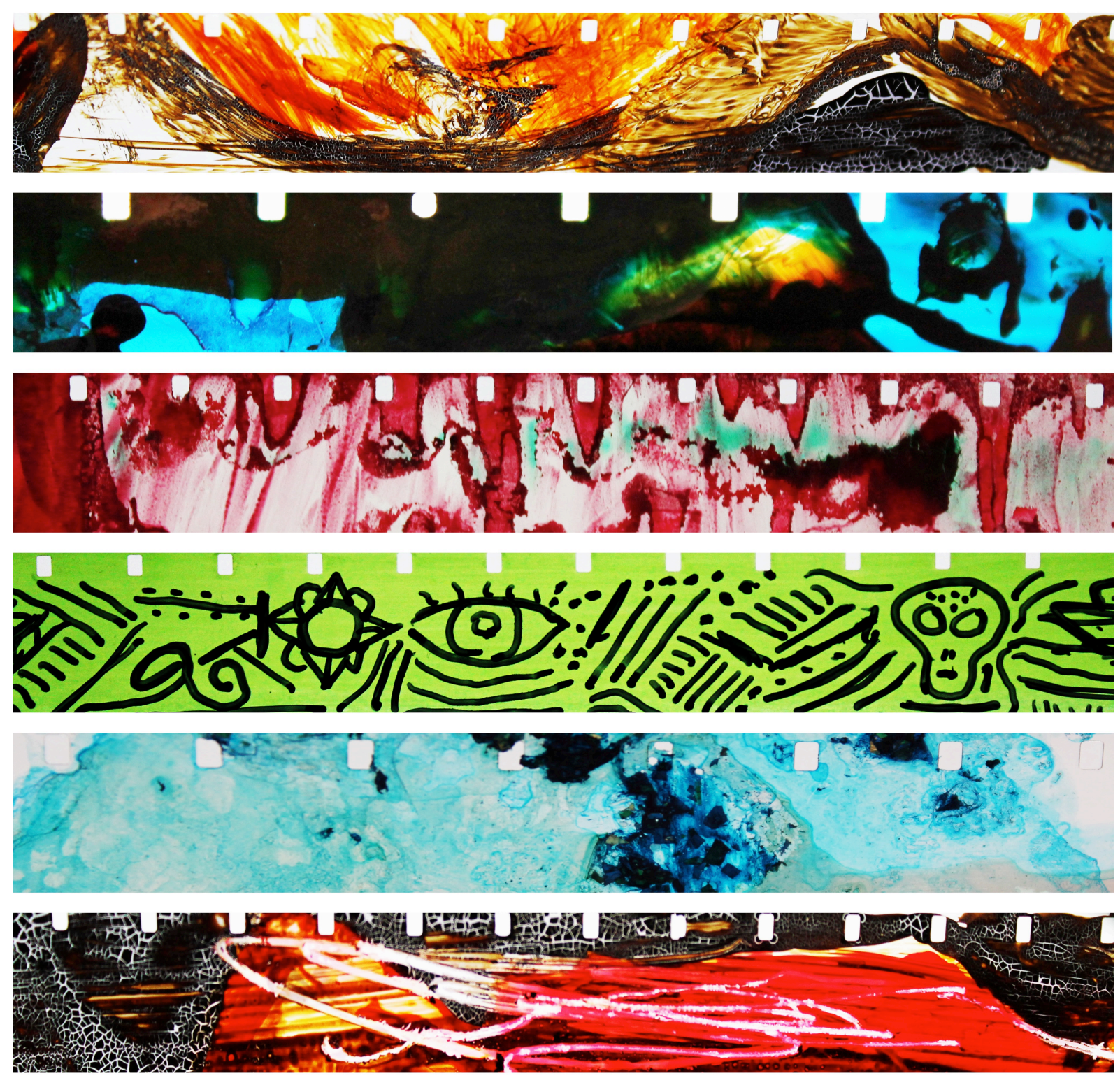

Figure 1 A selection of images created by the participants during the filmmaking workshops

Several critical moments occurred in relation to how the participants reacted and interacted to the workshop activities, particularly in how many responded to its expressive nature. At times when I engaged participants in conversation about their illustrations, whilst enthusiastic about the artistic nature of this approach, I was confronted with defensive disclaimers of their lack of artistic ability. Such self-deprecation was a common occurrence amongst all the participants. In one particular example, Hailey, one of the three female participants, compared what she was doing to a nursery activity. Throughout the workshop, Hailey was eager to experiment with the inks and demonstrate such experiments to me. However, whilst engaged and excited, she assured me that what I was asking her to do was childish "finger painting". 
In such instances, I have found myself unpacking the possible motivations for this selfdevaluation. Such downgrading appeared to be instinctually adopted to disguise insecurity and low self esteem, a disparaging strategy that appears to be entrenched within the general culture of the classroom. Paradoxically, describing the activity as infantile actually permitted Hailey to be more fully involved, expressive, and explorative, whilst safeguarding against critique as she attempted to lower my expectations of her skill level. During such moments, I made a conscious effort to remind the participants that their contributions were not being assessed and that the purpose of the activities was for experimentation, and, essentially, they were meant to be fun.

During these early workshops, the teacher approached the group about entering another inter-school competition, this time a filmmaking competition. The brief required us to produce a one minute short about a government sector of our choosing. The participants chose to focus their film on the emotional phases of education. Throughout this time, we had many, quite sophisticated, conversations surrounding the emotive and symbolic connotations of colour and music, where the participants drew up mood boards, music playlists, and a time line tracking the different developmental and transitioning phases of education, from nursery up to high school (McAra 2015). Treating the workshops as a production process, the pupils self-elected roles including Director, Production Manager, Sound Editor and artists. There was a notable shift in the type of participation that took place, perhaps induced by the notion of entering a competition, where I witnessed several pupils' transition from the role of participant to the role of co-researcher. I was struck by degree to which the pupils were identifying with highly abstract imagery and in defining the meaning of colour metaphorically. Emotions connoted through colour included loneliness, hatred, determination, joy and fascination, as well as assigning colours to symbolically represent childhood, innocence, growth and safety (see Figure 2). 


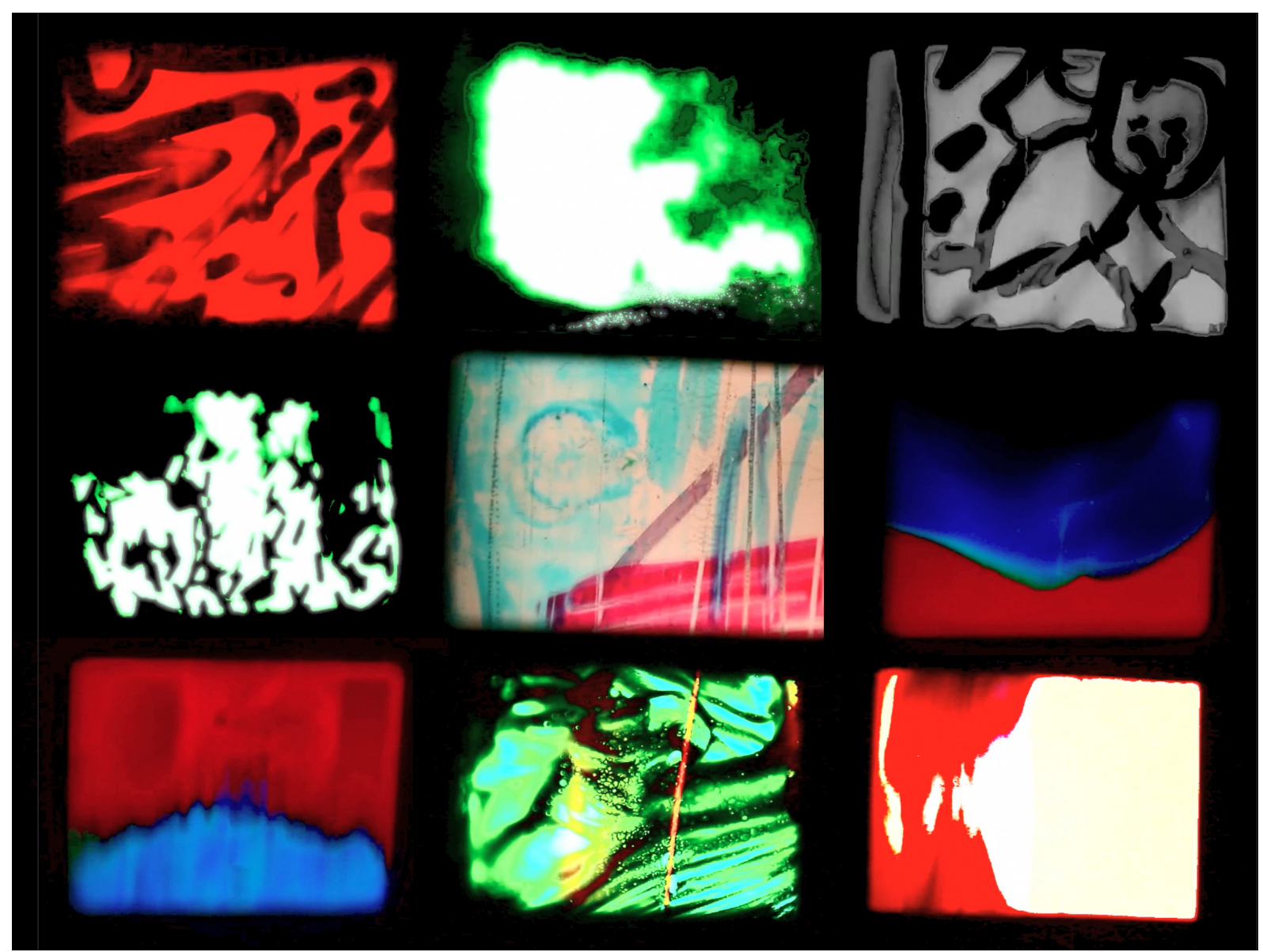

Figure 2 A selection of stills from the participant's final film

\section{Reflections}

As well as reflecting on how the participants were developing as co-researchers through the filmmaking process, I also became conscious of how my own role was fluctuating. I experienced a fundamental challenge when facilitating collaboration with this diverse group of individuals. I found it a necessity for achieving meaningful dialogue to, like a chameleon, consistently adapt my demeanour and conduct in-line with individual participants on a very bespoke and personalised basis (McAra forthcoming 2016). At this point within the fieldwork my instinct in managing this grew as I had become mindful of the individuals who required a little more guidance and encouragement and of those who had the confidence to assertively take the lead. With those less confident, I took on the role of participant, sitting down next them and taking part in the filmmaking activity, as described in the field note exert below:

“... I began working on my own piece of film, and together we sat, crafted, and conversed... I began the conversation by asking what they thought they would do after leaving school. Whilst Matt described wanting to get into construction, Lewis and Sam described their thoughts about possibly joining the Army or Royal Navy. We discussed the army and Iraq, where I offered a personal anecdote of a family member's involvement in the army. During this time, the conversation wove in and out of these personal anecdotes and discussion about the film. Sam then began experimenting with 
dipping the film into a cup of ink, taking it out, and drying it very quickly which lead to the film having a translucent dyed effect. Matt used his hands to thickly spread ink onto his film, commenting on the pearlescent, almost metallic effect it was creating." (Exert taken from field note recorded 20/10/14)

Through modelling the technique to these participants, they were able to follow in my footsteps before intuitively deviating away from my examples to work independently. With the more confident participants, I refrained from overt facilitation and advised them as a coresearcher through gently challenging their assertions and helping them with planning and organisation:

"I watched as this initial interaction unfolded between these two main sub teams Max, David and Joe focusing on the music and Hailey and Meghan working on the films visual content. They began by positioning themselves at opposite ends of the classroom. Both working autonomously, I suggested that as what they were each doing was going to be informing what the other was doing, they would need to start talking and working as a collective. Dialogue between the two groups ensued loudly across the classroom. Reiterating the fact that both groups needed to work together, Hailey and Meghan picked up their timeline and placed on the floor by the other group working on the computer. This location then became the site of collaborative activity for the rest of the period." (Exert taken from field note recorded 6/10/14)

Underpinning my roles, in both these examples, was the ability to nurture. At times I also became a mediator and advocate in negotiating with the more active participants an invitation for those more passively situated at the periphery, to join them at the hub of activity. This level of understanding and awareness of individuals' working style and character, which allowed for more meaningful interaction, only occurred with time and patience, and on the participants' own terms. On numerous occasions the participants sought individual ownership over specific responsibilities, techniques, and materials, making genuine collaboration challenging to facilitate. Whilst such self-mobilisation was encouraging in terms of harnessing agency, it was also often the cause of conflict and creative tensions, where my role would have to quickly transform to one of peacekeeper and diplomat.

Furthermore, I found it challenging to broker the often conflicting dynamics between the already established and firm classroom hierarchy set by the teacher with the collaborative and democratic culture I was striving to create. I felt at times the teacher inadvertently encroached on the participatory nature of the workshops when she either reprimanded pupils for misbehaviour or forcefully encouraged them to take part. Moments such as these drew my attention to the implications of implementing this study in the institutionalised setting of a school, nuances of which I acknowledge were most likely implicitly embedded in the conduct of the pupils as participants. For the duration of the research, the young people were at once both collaborative partners with me, as well as pupils in a classroom under the supervision of the teacher. In line with Spyrou (2011), who raises concerns over the effects of institutional settings, particularly the ingrained influence of established hierarchical power dynamics young people are subordinated by in the context of education, I too 
became mindful that the very setting of this research could be at odds with the underpinning democratic values of my methodology. Whilst I felt managing the group dynamics was my responsibility, I leant on the filmmaking process as a means of attempting to maintain an egalitarian culture within the classroom.

\section{Findings}

Reflecting on the efficacy of Direct Animation as a participatory film medium, I witnessed the process encourage the participants to be explorative, experimental, metaphorical, and highly creative, by working in a medium that does not strictly demand drawing ability. The participants collaboratively constructed a shared visual language completely of their own making, positioning them in control of what, and the degree to which, they disclosed their experiences and knowledge through. Reflecting on, and translating their knowledge and experiences metaphorically into abstract imagery and through the interpreted of music, colour, shapes and textures, the participants' final film was emotive, reflective and profound. In this respect, I draw on Schön's (1984) theory of reflection-in-action, where the participants reflectively interacted with and through the process of direct animation, working within the connotations of their illustrations, as opposed to what was literally been drawn. Here I also draw on Dewy's (1934) notion of how the aesthetic is experienced drawing on his concept of the Expressive Object. For Dewy, art should be viewed as an expression rather than a direct depiction. In the making of these films, the illustrations were a mode of self-expression rather than of representation or statement making. It was an emotional response embodied and expressed in and through the mark marking.

Additionally, the goal of entering the competition provided a common objective, helping to instil a sense of camaraderie, with the participants treating the process and their roles synonymous to that of a production team. Whilst the analogy of a production process brought about group cohesion, it also heightened autonomy through empowering individual participants to utilise their own newly acquired skills, in their self-elected roles. Created together, the process of making these films became a further opportunity for me to "experiential[ly] bond" (Wearing 2015) with the participants. As a method, the value of Direct Animation is located in the process, as opposed to finish artifact.

The aim in relation to my research question was to discern factors that motivate young people's sense of agency. A key contextual finding was that the participants were able to articulate a deep and insightful knowledge of their desired learning styles and have an acute awareness of the types of teaching activities that enabled and motivated them to learn and equally, the styles that did not. Many described an enhanced experience of learning and enjoyment in classes where teaching was premised on practical activities such as games and experiments, where the pupils were enabled to take a more physically active role in their learning. Within this, the majority of the participants indicated a correlation between didactic styles, their own classroom behaviour, and their relationship with particular teachers. Qualities sought in favoured and, more significantly, trusted teachers included 
being supportive, compassionate, dependable and nurturing, in some cases described as maternal and paternal figures. The pupils reported that such qualities demonstrated by a teacher would then be reciprocated through being more committed and attentive in their classes. Conversely, teachers less favoured were regarded as untrustworthy, uncaring and unreliable, where often the participants felt a sense of rejection, that they were not prioritized and in a losing competition with other, higher achieving pupils, for attention. In such cases, particular participants described feelings of frustration manifested as an apathetic attitude in these classes.

What became gradually more apparent was this group of young people were dealing with a complex mix of conditions and circumstances, both inside and outside of school. When discussing classroom behaviour, the participants reflected on how personal problems and adversities occurring in their lives outside of school can unintentionally manifest in disruptive and rebellious behaviour in school. Focusing on their goals and aspirations was mobilising the participants' motivation for their schoolwork and assessments, making motivated endeavours for their futures. However, when describing plans for their future post compulsory education, the participants alluded to anxieties about leaving the safety net of school. Several participants described looking forward to having more freedom, however seeking this and fulfilling their goals locally by staying close to home. Others, whilst communicating highly aspirational ambitions, appeared resigned to a despondent and pessimistic outlook, with an underlying inevitably of failure.

\section{Conclusion}

The entrenched culture of self-deprecation and self-disparagement that I observed in the classroom was suggestive of a somewhat fragile yet resilient personal agency. As I have argued, the young people deliberately masked their insecurities and low self-esteem to lower expectations of their skill level. Paradoxically this functioned as a self-empowering strategy. There are important lessons here for future research investigating at-risk, particularly younger, demographics. My research highlights the ways in which genuine insight can be gained by offering the pupils a creative activity that strived to foster autonomous learning, and to empower the pupils to harness their own agency as participants and co-researchers. Reflecting on how a participatory design approach can catalyse an emotive and reflective dialogue, I suggest the need for a sensitivity on behalf of the researcher to look for cues and seek out opportunities for experientially bonding with participants. With time and patience, these sometimes fleeting opportunities can be built upon incrementally so as to cultivate moments of genuine engagement, and meaningful and authentic dialogue. 


\section{References}

Broadley. C. (2013) Visualising Human-Centred Relationships: A Toolkit for Participation, thesis completed at The Glasgow School of Art.

Broadley, C. and McAra, M. (2013) Making, Using and Interpreting Design Probes: How Subjective is Participation?, DRS//CUMULUS, 2nd International Conference for Design Education Researchers, Oslo.

Dewy, J. (1980) Art as Experience, Perigee Books.

Fergusson, R. (2013) Against Disengagement: non-participation as an object of governance, Research in Post-Compulsory Education, 18:1-2, pp. 12-28, DOI: 10.1080/13596748.2013.755806.

Finlay, I., Sheridan, M., McKay, M., and Nudzor, H. (2010) Young People on the Margins: in need of more choices and more chances in twenty-first century Scotland, British Educational Research Journal (Vol) 36:5, pp. 851-867, DOI: 10.1080/01411920903168532.

Furlong, A. (2006) Not a very NEET solution representing problematic labour market transitions among early school-leavers. Work, Employment and Society (Vol 20: 3), pp. 553-569.

Furlong, A., Cartmel, F., A, Biggart., H, Sweeting., and P, West. (2003) Youth Transitions, Patterns of Vulnerbalility and Porcesses of Social Inclusion, Scottish Executive Social Research.

Gauntlett, D. (1997) Video Critical, Children, the Environment and Media Power, John Libbey Media.

Gauntlett, D. (2007) Creative Explorations, New Approaches to Identities and Audiences, Routledge.

Gauntlett, D. (2008) Losing sight of the ball?: Children, media and the environment, international Broadcasting Symposium, University of Manchester.

Harkins C, Egan J. (2013) The Rise of In-work Poverty and the Changing Nature of Poverty and Work in Scotland: what are the implications for population health?. Glasgow: GCPH.

Heyes, K, R. (2010) The Role of Time in Exploratory Drawing. Diss. College of Fine Arts, University of New South Wales, Sydney.

Koskinen, I., Zimmerman, J., Binder, T., Redstrom, J., and Wensveen, S. (2011). Design research through practice: From the lab, field, and showroom. Elsevier.

Literat, I. (2013) "A Pencil for Your Thoughts": Participatory Drawing as a Visual Research Method with Children and Youth, International Journal of Qualitative Methods (Vol 12): pp. 84-98.

Levitas, R., Pantazis, C., Fahmy, E., Gordon, D., Lloyd, E. R. R. R., and Patsios, D. (2007) The Multidimensional Analysis of Social Exclusion, London: Cabinet Office.

Lomax, H, et al. (2011) The Politics of Performance: Methodological Challenges of Researching Children's Experiences of Childhood Through the Lens of Participatory Video, International Journal of Social Research Methodology (Vol 14.3): pp. 231-243.

Lunch, N. and Lunch, C. (2006) Insights into Participatory Video; A Handbook for the Field, InsightShare.

McAra, M. (forthcoming 2016) Sustaining Engagement to Create Resilient Communities: how a collaborative design approach can broker and mobilise practitioner-participant interaction, The International Journal of Arts and Design Education.

McAra, M. (2015) Animating through Animation: how artistic practice gives voice to young people living in poverty, Scottish Justice Matters: poverty, inequality and justice (Vol. 3.3): pp. 15.

McIntyre, A. (2007) Participatory Action Research (Vol. 52). Sage Publications.

Milne, E J. Mitchell, C. and de Lange, N. (2012) Handbook of Participatory Video. Rowman and Littlefield. 
Bonding through Designing; how a participatory approach to videography can catalyse an emotive and reflective dialogue with young people

Nelson, J., and O'Donnell, L. (2012) Approaches to Supporting Young People Not in Education, Employment Or Training, a Review. National Foundation for Educational Research.

Nudzor, H. (2010) Depicting young people by what they are not: conceptualisation and usage of NEET as a deficit label, Educational Futures (Vol 2.2): pp. 12-25.

Reason, P. and Bradbury, H. (2006) Handbook of Action Research: Concise Paperback Edition, Sage

Sanders, E. B. N. (2002) From User-centered to Participatory Design Approaches. Design and the social sciences: Making Connections, pp. 1-8.

Sanders, E. and Stappers, P J. (2008) Co-creation and the New Landscapes of Design, Co-design (Vol 4.1): pp. 5-18.

Schön , D A. (1983) The Reflective Practitioner; How Professionals Think in Action, Basic Books Inc.

Scottish Executive. (2006) More Choices, More Chances: a Strategy to reduce the proportion young people not in education, employment or training in Scotland, Scottish Executive, Edinburgh.

Scottish Executive. (2005) Literature Review of the NEET Group, http://tinyurl.com/hqkhhpj (accessed 14 Novemeber, 2015).

Scottish Government. (2015) High level summary of statistics trend update: Not in employment, education, or training (NEET) 22 $2^{\text {nd }}$ July. http://tinyurl.com/z4yfrwc (accessed 07 March, 2016).

Scottish Government. (2012) Opportunities for All: Supporting all young people to participate in post16 learning, training or work, Crown Copyright.

Scottish Government, Social Research. (2015) Children, Education and Skills; Consequences, risk factors, and geography of young people not in education, employment or training (NEET), Crown Copywrite. http://tinyurl.com/np5mlgp (accessed 11 November, 2015).

Shaw, J. (2012) Contextualising empowerment practice: negotiating the path to becoming using participatory video processes. Diss. The London School of Economics and Political Science (LSE).

Simonsen, J., and Robertson, T. (Eds.). (2013) Routledge International Handbook of Participatory Design. Routledge.

Simmons, R., Russell, L., and Thompson, R. (2013) NEET young people and the labour market: working on the margins, http://tinyurl.com/ztotm6d (accessed 14 November, 2015).

Spielhofer, T., Benton, T., Evans, K., Featherstone, G., Golden, S., Nelson, J. and Smith, P. (2009) Increasing Participation: understanding young people who do not participate in education or training at 16 and 17.

Spyrou, S. (2011) The Limits of Children's Voices: From Authenticity to Critical, Reflexive Representation, Childhood (Vol 18.2): pp. 151-165.

Stake, R. E. (1995) The Art of Case Study Research. Sage.

Swann, C. (2002) Action Research and the Practice of Design. Design Issues, (Vol 18.1): pp. 49-61.

Sweenie, S. (2009) 'NEETS': perceptions and aspirations of young people Not in Education, Employment or Training. Diss. University of Glasgow.

Thompson, R., Russell, L., and Simmons, R. (2014) Space, Place and Social Exclusion: an ethnographic study of young people outside education and employment. Journal of Youth Studies, (Vol 17.1): pp. 63-78.

Visser Sleeswijk, F. (2009) Bringing the Everyday Life of People into Design, Technische Universiteit Delft.

Wearing, M. (2015) The Experiential Bond, Youth 'At the Margins'. SensePublishers, pp. 65-86. 
Whittaker, L. (2010) Structures of Recognition: A Dialogical Analysis of the Experiences of a Group of Young People within a Scottish Local Authority Access Programme, International Journal for Dialogical Science.

Whittaker, L. (2008) "Scotland's Shame": A Dialogical Analysis of the Identity of Young People Not in Education, Employment or Training. Psychology and Society 1: pp. 54-64.

Wilson, S. and Milne, E J. (2013) Young People Creating Belonging; Space, Sounds and Sight, Economic and Social Research Council, http://tinyurl.com/hck4nr6, (Accessed 28 January, 2014).

Yang, K. (2013) A Reflection on a Participatory Video Project: Possibilities and Challenges for Promoting Participatory Cultures among Adult Learners, The Urban Review: pp. 1-13.

Yates, S. and Payne, M. (2006) Not so NEET? A critique of the use of 'NEET' in setting targets for interventions with young people, Journal of Youth Studies (Vol, 9.3): pp. 329-344.

Yin, R. (1994) Case study research: Design and methods, London: Sage.

Zimmerman, J., Stolterman, E. and Forlizzi, J. (2010) An Analysis and Critique of Research through Design: towards a formalization of a research approach, Proceedings of the 8th ACM Conference on Designing Interactive Systems. ACM.

About the Author:

Marianne McAra is currently studying for a PhD at The Institute of Design Innovation at The Glasgow School of Art, where she is also a Graduate Teaching Assistant for design Master students. Marianne has a Masters in Design Innovation. 